This item was submitted to Loughborough's Research Repository by the author.

Items in Figshare are protected by copyright, with all rights reserved, unless otherwise indicated.

\title{
Fabric based frequency selective surfaces using weaving and screen printing
}

PLEASE CITE THE PUBLISHED VERSION

http://dx.doi.org/10.1049/el.2013.2314

\section{PUBLISHER}

(c) The Institution of Engineering and Technology

\section{VERSION}

AM (Accepted Manuscript)

\section{LICENCE}

CC BY-NC-ND 4.0

\section{REPOSITORY RECORD}

Seager, R.D., Alford Chauraya, J. Bowman, M. Broughton, Rachel Philpott, and Nithikul Nimkulrat. 2019. "Fabric Based Frequency Selective Surfaces Using Weaving and Screen Printing". figshare. https://hdl.handle.net/2134/13766. 
This item was submitted to Loughborough's Institutional Repository (https://dspace.lboro.ac.uk/) by the author and is made available under the following Creative Commons Licence conditions.

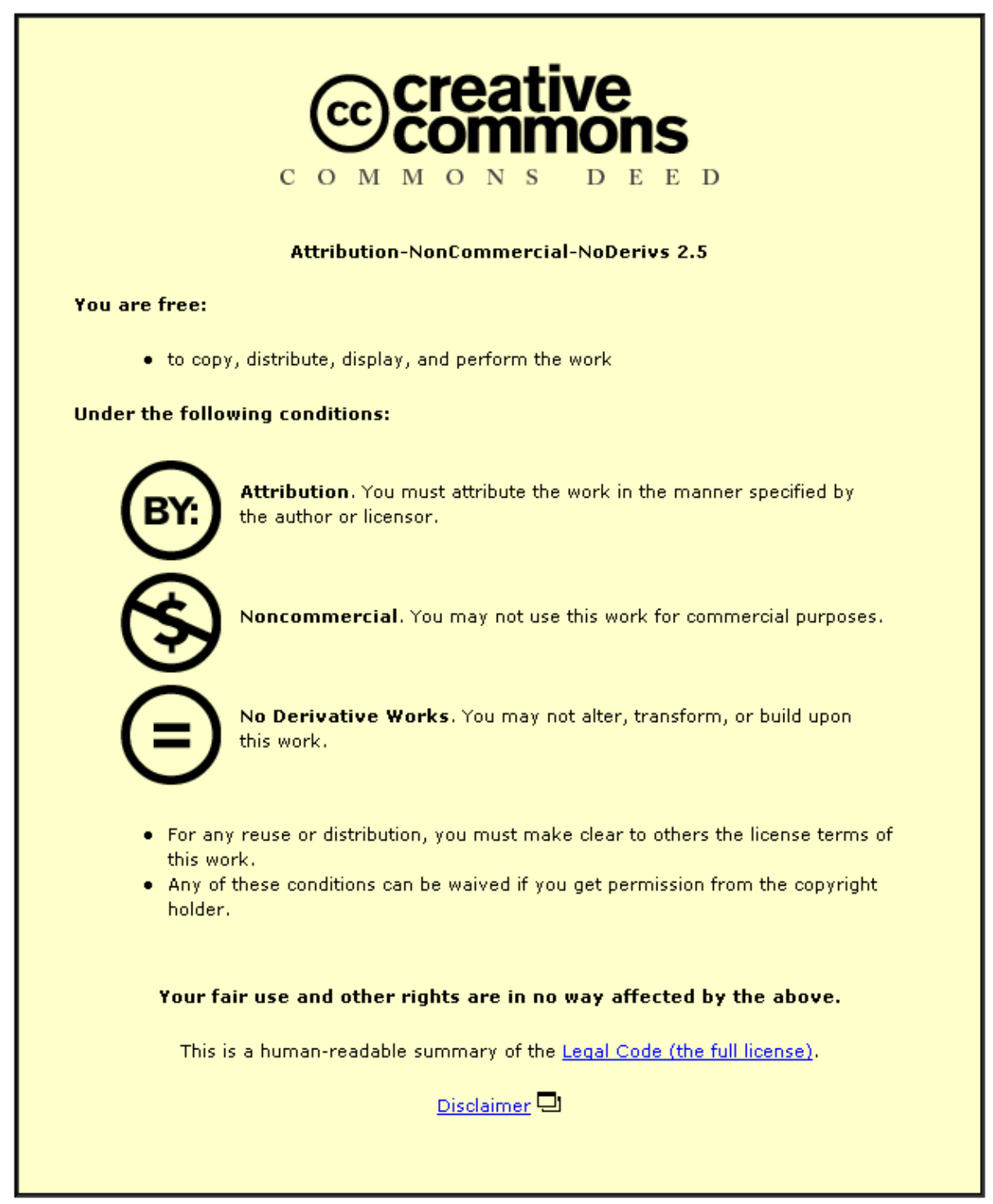

For the full text of this licence, please go to: http://creativecommons.org/licenses/by-nc-nd/2.5/ 


\section{Fabric based frequency selective surfaces (FSS) using weaving and screen printing}

R. D. Seager, A.Chauraya, J. Bowman, M. Broughton, R. Philpott and N. Nimkulrat.

\begin{abstract}
Two examples of fabric based Frequency Selective Surfaces (FSS) are presented in this paper. The FSS surfaces are produced using screen printing and weaving. Both measured and simulated data is presented showing excellent agreement and performance for the FSS surface when compared with simulated data. The performance of these samples point towards a useful screening technique using fabric hangings and wall coverings in a range of applications where temporary electromagnetic (EM) wave ingress or egress needs to be controlled.
\end{abstract}

Introduction: There is an huge body of research on FSS and related arrays $[1,2]$. In a similar vein, there are many publications reporting on wearable antennas and antenna systems [3, 4]. Publications on fabric based FSS are rare [5]. Research work at Sheffield and Nottingham Trent University [6] has extended their study [5] to considering knitted substrates with conductive vias. This paper presents results for two different fabric based square loop FSS. The two FSS considered are produced using weaving and screen printing. Both samples show excellent transmission responses that are similar to those one might expect from a copper based FSS of the same type.

Modelled FSS Details: The FSS picked for this study is a square loop array as shown in Fig 1. This is a simple resonator structure which is easy to construct and simulate. Resonator dimensions and spacing are shown in the Fig. 1 . The periodicity in both directions is $34 \mathrm{~mm}$. The FSS was simulated using CST Microstripes ${ }^{\mathrm{TM}}$ with a silver conductor. With no dielectric support the resonant frequency was $2.82 \mathrm{GHz}$. When a $0.1 \mathrm{~mm}$ dielectric layer with $\varepsilon_{\mathrm{r}}=2.5$ was inserted the resonant frequency moved to $2.81 \mathrm{GHz}$, showing the small effect a very thin supporting layer may have on the resonant frequency of an FSS. Fabric layers are often thicker than this and the resonant frequency moves to $2.62 \mathrm{GHz}$ if the substrate thickness in the simulation is increased to
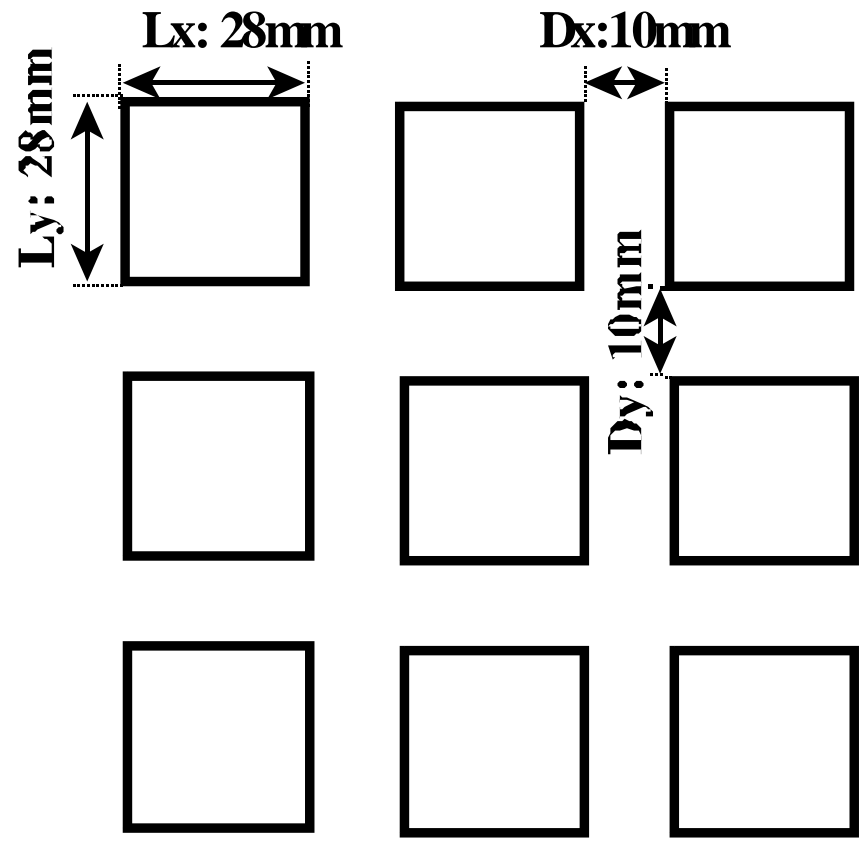

$0.5 \mathrm{~mm}$.

Fig 1: Base FSS dimensions (Not drawn to scale).Conductor thickness is $0.5 \mathrm{~mm}$.

Fabric Sample Details: The dimensions of the two fabric FSS reported here are given in Table 1. These differ slightly from the simulated FSS.
There is clearly a constraint in terms of weaving as the position of the conductors must coincide with the weft and warp fibres. The screen used in screen printing will also affect the edge position and definition of the conductors.

Table 1: Dimensions and measured resonant frequencies of evaluated samples. Dimensions in $\mathrm{mm}$.

\begin{tabular}{|l|c|c|c|c|c|c|}
\hline & Lx & Ly & Dx & Dy & $\begin{array}{c}\text { Line } \\
\text { Width } \\
(\mathbf{m m})\end{array}$ & $\begin{array}{c}\mathbf{f}_{\text {res }} \\
(\mathbf{G H z})\end{array}$ \\
\hline Amberstrand & 28 & 28 & 10 & 11 & 0.03 & 2.5 \\
\hline Screen Print & 28 & 28 & 11 & 11 & 1.1 & 2.44 \\
\hline
\end{tabular}

The woven sample presented here used two picks of Amberstrand [7] 66 Silver coated fibre in both $\mathrm{X}$ and $\mathrm{Y}$ directions. The base material was woven from 2/60 mercerised natural cotton at 96 ends per inch in the warp and white spun polyester sewing thread at approximately 55 picks per inch in the weft.

The screen printed sample was produced using Metalon HPS-021LV silver paste, by Novacentrix, printed on a $100 \%$ polyester base layer. A $64 \mathrm{~T}$ mesh and a V-cut squeegee were used for this sample. The sample was cured at $180^{\circ} \mathrm{C}$ for 10 minutes.

Fig. 2 shows photographs of the corner of one single fibre Amberstrand loop and the screen printed square loop.

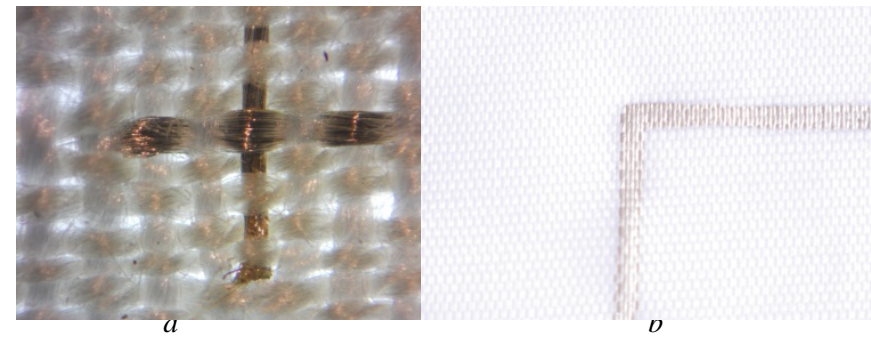

Fig 2: Photographs of the two square loop samples.

a Typical loop corner showing contact point and extended terminations after removal of floats. Floats removed from left hand side and lower side of image. 25 x magnification. Conductor thickness : $0.013 \mathrm{~mm}$

b Screen printed FSS. Conductor thickness : $1.1 \mathrm{~mm}$

Results: Both FSS screens performed extremely well in plane wave tests at normal incidence in the Wireless Communications Research Group at Loughborough University. Fig. 3 shows the measured and simulated transmission for the woven FSS and fig. 4 shows the transmission response for the screen printed FSS. The measurements show a clear resonance close to the design frequency with an insertion loss better than $30 \mathrm{~dB}$ at the resonance in each case. The response shows the presence of a grating lobe around $7.5 \mathrm{GHz}$. The measured and simulated results are in close agreement, both in frequency and in

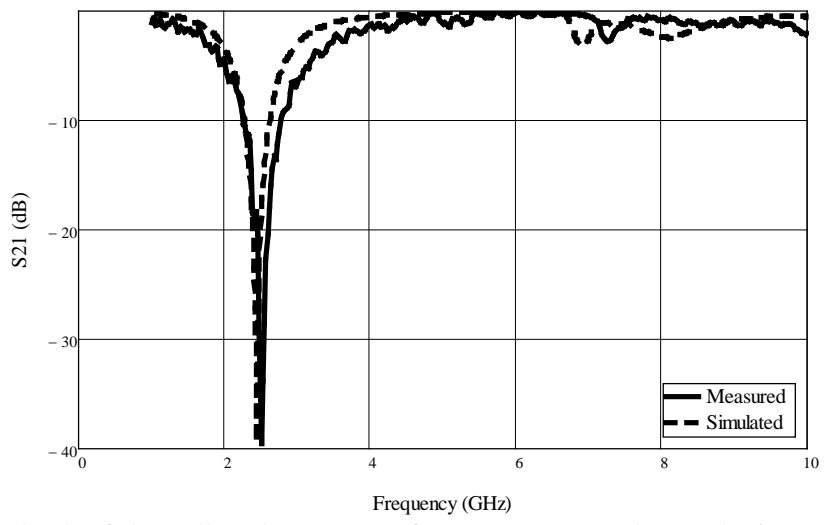

the depth of the null at the resonant frequency. From the results it can 
Fig.3: Transmission response of woven square loop FSS using two picks of Amberstrand silver. Effective Thickness 0.03mm.

be seen that both metallisations appear to show a high conductivity, producing good quality surfaces.

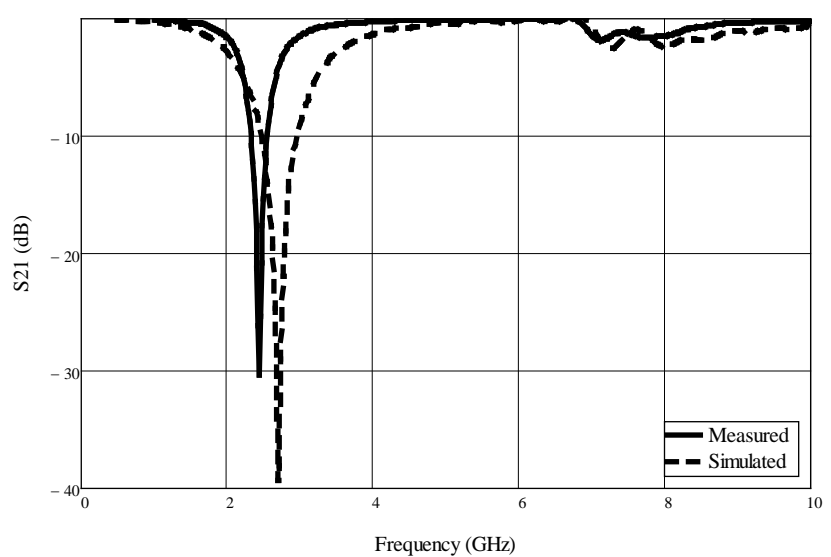

Fig. 4: Transmission response of screen printed square loop FSS using silver paste

Conclusions: Producing conductive components using techniques drawn from fabric production have been demonstrated by many authors over a range of different frequencies. The textile surfaces here demonstrate that similar techniques may be used to produce fabrics that will be able to be used to control ingress of electromagnetic waves at microwave frequencies into parts of buildings. The use of fabrics, which can be temporary and easily controlled, points to applications in conference facilities, art galleries, museums and screening in clothing. The range of FSS elements available, linked with the highly automated fabrics industry point towards the production of a range of fabric screens that will be both aesthetically pleasing and practical in nature.

Acknowledgments: This work was supported by a "Bridging the Gap" grant awarded to the authors by Loughborough University.

Fig. 2a is reproduced courtesy of Matthew Broughton of the School of the Arts at Loughborough University.

R. D. Seager, and A.Chauraya are with the School of Electronic, Electrical and Systems Engineering, Loughborough University, Loughborough, LE11 3TU, U.K.

E-mail: r.d.seager@lboro.ac.uk

J. Bowman, M. Broughton, R. Philpott, N. Nimkulrat and Matthew Broughton are with the School of the Arts, Loughborough University, Loughborough, LE11 3TU, U.K

\section{References}

1. Vardaxoglou, JC (1997) Frequency Selective Surfaces: Analysis and Design, Research Studies Press, John Wiley \& Sons Inc, ISBN: 0471965502

2. Parker, E.A. ; Savia, S.B. Microwaves, Antennas and Propagation, IEE Proceedings Volume: 151 , Issue: 1. Digital Object Identifier: 10.1049/ip-map:20040207 Publication Year: 2004 , Page(s): 77 - 80

3. Kennedy TF., Fink PW., Chu AW, Champagne NJ., Lin GY. and Khayat MA. "Body-Worn E-Textile Antennas: The Good , the Low-Mass , and the Conformal," IEEE Trans. Antennas and Propagation, vol. 57, no. 4, pp. 910-918, 2009.

4. Cottet D, Grzyb J, Kirstein T, \& Troster G. Electrical characterization of textile transmission lines. IEEE
Transactions on Advanced Packaging, 26(2), 182-190, (2003). doi:10.1109/TADVP.2003.817329

5. Tennant, A., Hurley, W. and Dias, T. Experimental knitted, textile frequency selective surfaces. Electronics Letters, $25^{\text {th }}$ October 2012, Vol. 48, No. 22.

6. Tennant, A., Hurley, W. and Dias, Knitted textile high impedance surface with integrated conducting vias, Electronics Letters, $3^{\text {rd }}$ January 2013, Vol. 49, No. 1.

7. Amberstrand: http://www.metalcladfibers.com/amberstrandfiber/ (Last accessed 18/12/12). 

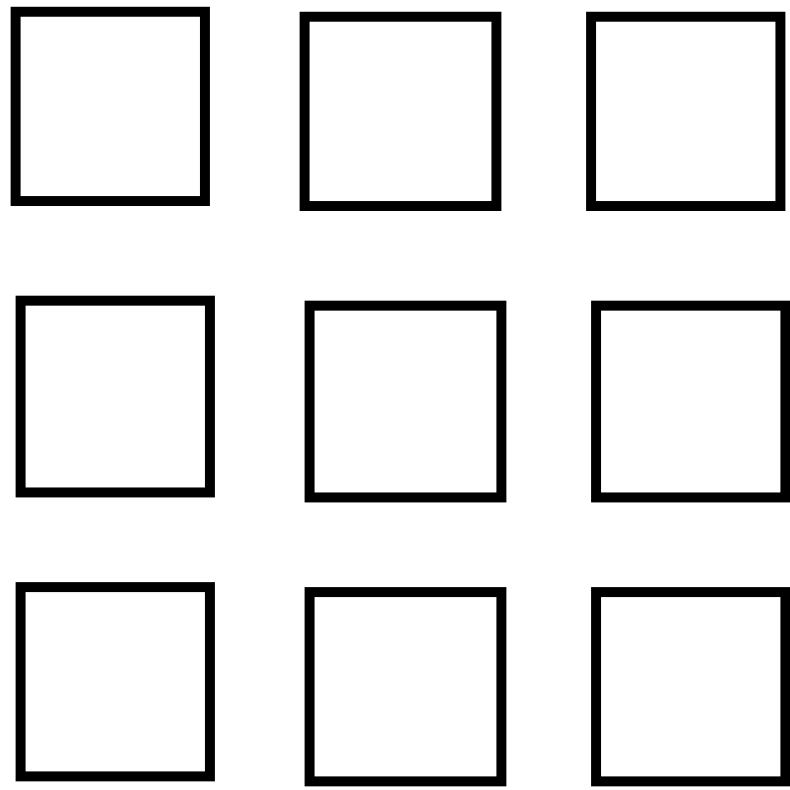

Fig 1

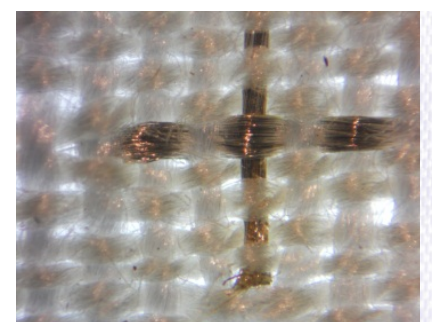

Fig 2

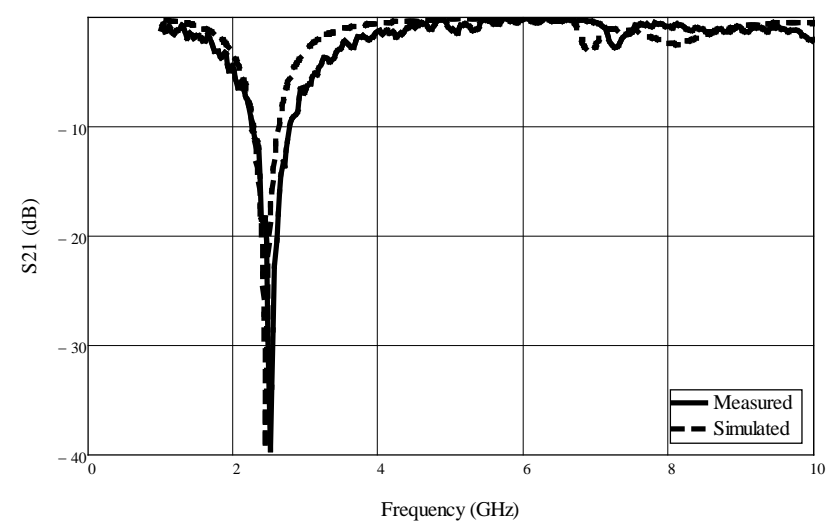

Fig 3

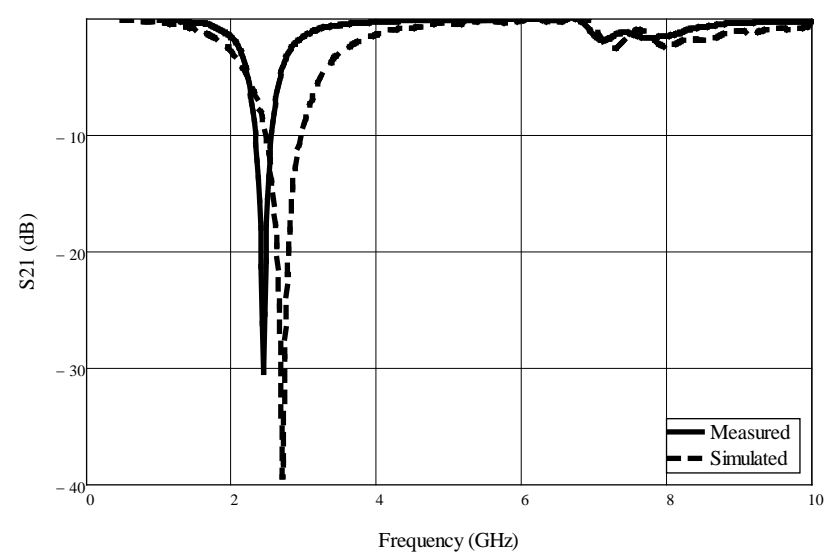

Fig 4 